\title{
Topuk ağrısı
}

\author{
Heel pain
}

\author{
Mustafa Akif Aşansu, Yakup Yıldırım
}

Marmara Üniversitesi Tıp Fakültesi, Pendik Eğitim ve Araştırma Hastanesi, Ortopedi ve Travmatoloji Anabilim Dalı, İstanbul

Topuk ağrısı kendine özgü belirtiler veren, çok farklı etiyolojik nedenlere bağlı olabilen ve ortopedi polikliniğinde sıklıkla karşılaştığımız bir yakınmadır. Uygun bir tedaviye başlanabilmesi için hastanın şikâyetleri iyi dinlenmeli, anamnezi iyi alınmalı ve muayenesi iyi yapılmalıdır. Bütün bunlar bizi doğru tanıya götürecektir. Topuk ağrısını oluşturan etkeni saptamadan yapılan, ağrıya yönelik palyatif tedavi başarısızlıkla sonuçlanmaktadır. Bu nedenle topuk ağrısının lokalizasyonuna, etiyolojik etkene ve anatomik yapılara göre ayrı ayrı sınıflandırılması tanı koymada büyük kolaylık sağlamaktadır. Ancak ağrı lokalizasyonu tanıda belirleyici en önemli faktördür.

Ağrı nedeni tam olarak ortaya koyulmadan yapılan tedaviler hem yarar sağlamaz hem de tabloyu daha da ağırlaştırabilir. Çoğunlukla yanlış ayakkabı kullanımına bağlanan ve kalkaneal spur tanısıyla yeterli tetkik yapılmadan eksik tedavi edilen bu yakınma, iyi irdelendiğinde sistemik bir hastalığın ilk belirtisi ya da cerrahi girişim gerektiren bir tablo olarak karşımıza çıkabilmektedir. Topuk ağrısını basit bir yakınma olarak değerlendirmemek gerekir. Nedene yönelik tüm tetkiklerin yapılması, çok fazla tedavi seçeneği arasından uygun olanın saptanması kısa sürede rahatlık sağlamanın en doğru yoludur.

Anahtar sözcükler: topuk ağrısı; plantar fasiit; kalkaneal spur; Aşil tendiniti
Heel pain is a complaint frequently encountered in orthopaedic clinics that has peculiar symptoms and may have various etiological causes. A good history with detailed annotation of complaints and a comprehensive physical examination enable the commencement of an appropriate treatment. These will lead us to the correct diagnosis. A palliative treatment of the pain without determination of the factors that cause heel pain will result in failure. Due to these complexities, a classification of heel pain into subcategories, such as the localization of the pain, etiological factors and anatomical structures, provides great convenience for diagnosis. However, the most important factor in establishing the diagnosis is the localization of the pain.

A treatment administered without revealing the exact cause of the pain does not provide a benefit, and moreover aggravate the existing clinical table. A better assessment of this complaint, which is mostly attributed to the use of inconvenient footwear and undertreated with the diagnosis of calcaneal spur without executing an adequate examination, can be presented as an initial symptom of a systemic disease or a clinical picture requiring surgical intervention. The most accurate way to ensure fastest recovery is investigation of the causes entirely and determination of the most appropriate treatment option.

Key words: heel pain; plantar fasciitis; calcaneal spur; Achilles tendinitis
T opuk günlük yaşamımızda fiziksel bir dayanak noktası olarak görev yapar. ilkel çağların zor koşullarındaki çıplak olan topuğun günümüz dünyasının şartlarında bile hâlâ ağrılı olabilmesi anatomik yapısındaki özelliklerinden dolayıdır. Gelişen yaşam şartları ve ayakkabı değişimlerinden fazlasıyla etkilenir.

Topuk ağrısı kendine özgü belirtiler veren, çok farklı etiyolojik nedenlere bağ|ı olabilen ve ortopedi polikliniğinde sıklıkla karşılaştığımız bir yakınmadır. ${ }^{[1]}$ Uygun bir tedavi başlanabilmesi için hastanın şikâyetleri iyi dinlenmeli, anamnezi iyi alınmalı ve muayenesi iyi yapılmalıdır. Bütün bunlar bizi doğru tanıya götürecektir.

Ağrının lokalizasyonu, süresi, yayılımı, gün içinde maksimum olduğu dönemi, atletik aktivitelerle olan ilişkisi ayrıntılı bir şekilde sorgulanmalıdır. ${ }^{[2]}$ Hastanın mevcut kronik rahatsızlıkları, son dönemdeki varsa kilo değişiklikleri dikkate alınmalıdır. ${ }^{[2]}$ Ayrıca muayenede tüm alt ekstremite, hatta lumbar vertebralar unutulmamalıdır. Ayak yapısı, yürüyüş paterni göz önüne alınmadan, basarak çekilen iki yönlü ve oblik grafilerle

- İletişim adresi: Dr. Mustafa Akif Aşansu, Marmara Üniversitesi Tıp Fakültesi, Pendik Eğitim ve Araştırma Hastanesi, Ortopedi ve Travmatoloji Anabilim Dalı, İstanbul Tel: 0532 - 2600605 e-posta: mustafa_asansu@hotmail.com

- Geliș tarihi: 16 Eylül 2013 Kabul tarihi: 27 Kasım 2013 
değerlendirilmeden topuk ağrısının tanı ve tedavisi yapılmamalıdır.

Topuk ağrısını oluşturan etkeni saptamadan yapılan, ağrıya yönelik palyatif tedavi başarısızlıkla sonuçlanmaktadır. Bu nedenle topuk ağrılarının ağrının lokalizasyonuna, etiyolojik etkene ve anatomik yapılara göre ayrı ayrı sınıflandıııması tanı koymada büyük kolaylık sağlamaktadır. ${ }^{[2]}$ Ancak ağrı lokalizasyonu tanıdaki en belirleyici faktördür (Şekil 1). ${ }^{[2]}$

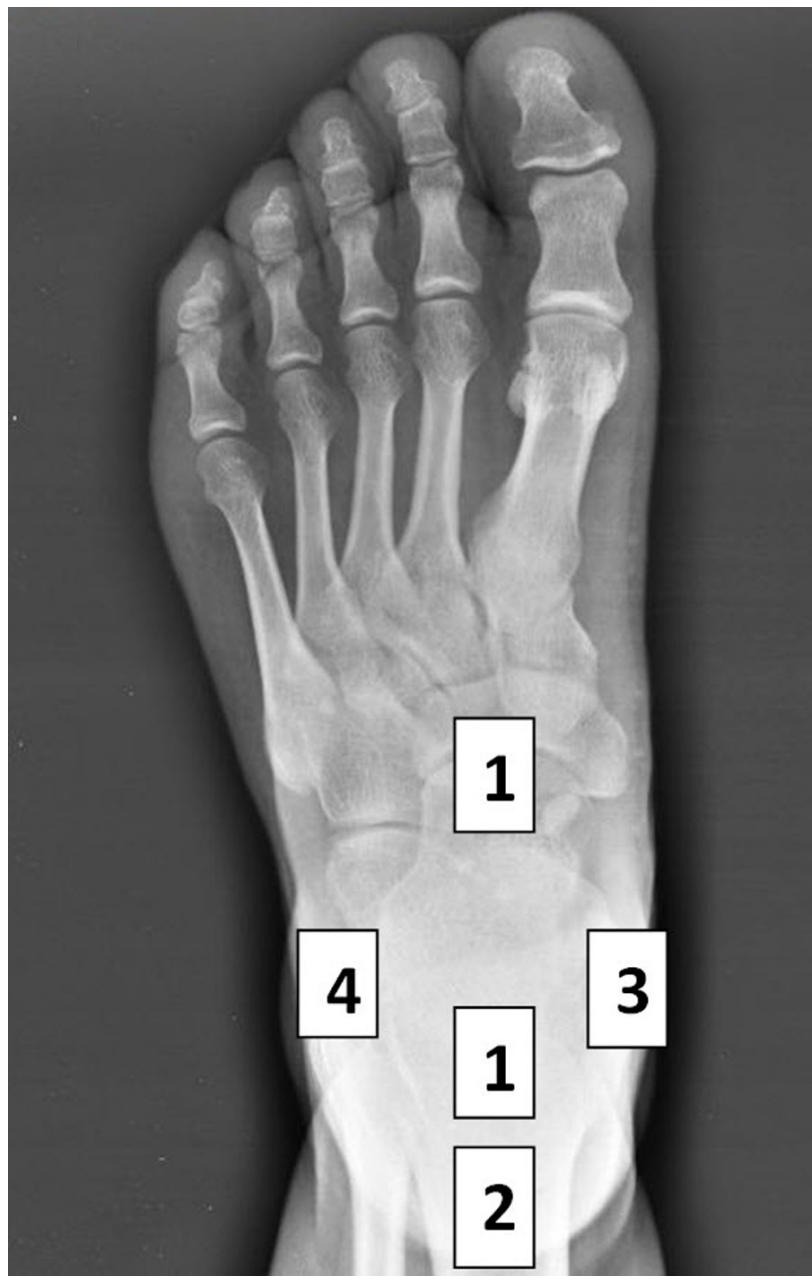

Şekil 1. Topuk ağrısı, ağrının lokalizasyonuna göre sınıflandığında dörde ayrılır:

1- Plantar: Proksimal ve distal plantar fasiit, plantar fasyanın yırtılması, kalkaneal spur, yağ yastığı atrofisi dejenerasyonu ve inflamasyonu, kalkaneus stres kırıkları, kalkaneus tümörleri ve Baxter sinirinin sıkışması vb.

2- Posterior: Retrokalkaneal bursit, yüzeyel aşil bursiti, kalkaneal egzostos, Aşil tendiniti ve seronegatif artritlere eşlik eden entesopatiler vb.

3- Mediyal: Tarsal tünel sendromu, tibialis posterior tendiniti ve kronik flexor hallucis longus tendiniti vb.

4- Lateral: Peroneal tendinit vb.

\section{AĞRININ LOKALIZASYONUNA GÖRE SINIFLANDIRMASI}

Topuk ağrısı, ağrının lokalizasyonuna göre sınıflandığında plantar, posterior, mediyal ve lateral olarak dörde ayrilır.

\section{Plantar topuk ağrısı}

Plantar fasiit, plantar fasyanın yırtılması, kalkaneal spur, yağ yastığı atrofisi, dejenerasyonu ve inflamasyonu, kalkaneus stres kırıkları, kalkaneus tümörleri en önemlileridir. Her topuk darbesinde yağ yastığı tampon görevi yapar. ${ }^{[3]}$ Sağlıklı orta yaş bir erkek ortalama $82 \mathrm{~m} /$ dakika hızında yürür. Bu yürüyüş hızı vücut ağırlığının \%110'u gücünde bir etki ile dakikada 58 topuk darbesiyle sonuçlanır. Bir koşu esnasında bu güç \%20 0'lere varmaktadır. 70 kg'lik bir insanın ortalama 23 $\mathrm{cm}^{2}$ lik topuk yağ yastığı üzerine her adımda verdiği yük yürürken $5 \mathrm{~kg} / \mathrm{cm}^{2}$ ve koşarken $9,3 \mathrm{~kg} / \mathrm{cm}^{2}$ dir. $^{[2]}$ Anatomik ve histolojik çalışmalar yağ yastığının olağanüstü makro ve mikro yapılarının bu yüksek beklentilere karşıık verecek özellikte tasarlanmış olduğunu göstermiştir. ${ }^{[4-7]}$

\section{Plantar fasiit}

Plantar topuk ağrısının en sık nedenidir. ${ }^{[2]}$ Ortalama görülme yaşı 45'tir. Kadınlarda erkeklere oranla iki kat daha fazla görülür. Kalkaneusun mediyal tuberositasından köken alan, ayağın mediyal plantar kısmında seyreden, kalın fibröz bant yapısında olan fasyanın inflamasyonu ve kalınlaşması sonrası meydana gelir. ${ }^{[2,8]}$ Fasyanın aşıı irritasyonu ve tekrarlayıcı gerilmesi sonucu mikro yırtıklar ve yapışma yerinde zorlanmalar oluşur. ${ }^{[2]}$ Hastalar çoğunlukla obezdir. ${ }^{[9]}$ Şikâyetler iki taraflı olabilir. Fasya yürümeyi zorlaştıracak kadar ağrılı ve inflame olabilir. Sabahları hasta ayakları üzerine ilk kalktığında şiddetli ağrısı olur. ${ }^{[2]}$ Hastanın ilk birkaç adımla başlayan, gün içinde azalan ve gün bitiminde tekrar ortaya çıkan tipik bir ağıı seyri vardır. Parmakların ucunda yürümeyle, parmakların pasif dorsifleksiyonuyla ve plantar fasya üzerine basmakla oluşan hassasiyet tanıda yardımcı olur (Şekil 2). ${ }^{[2,10,11] ~ K a l k a n e a l ~ s p u r ~ a g ̆ r ı-~}$ nın nedeni değil, patolojinin sonucudur. Topuk ağrısı olanların \%50'sinde kalkaneal spur görülebilir. Ancak topuk ağrısı olmayan populasyonun \% 16 'sında da yine kalkaneal spur görülebilmektedir. ${ }^{[12,13]}$ Ayrıca Du Vries ve Tanz spur origosunun flexor digitorum brevis' in başlangıç yeri olduğunu ve plantar fasya ile ilgisi olmadığını da göstermişlerdir. ${ }^{[2]}$ Bu nedenle tüm kalkaneal spurlar ağrı nedeni olarak değerlendirilmemelidir. Germe egzersizleri çoğu zaman plantar fasiitin neden olduğu ağrıyı ve kasılmaları hafifleterek rahatlatır. Uzun süreli ayakta kalmalar, uzun aktiviteler, egzersizler ve koşma sonraSı ağrı yoğunlaşarak şiddetlenir. ${ }^{[1,2,14-21]}$ Topuk ağrısına 
kalkaneusun mediyal tuberositasındaki hassasiyet de eşlik eder. Plantar fasiiti olan hastaların Aşil tendonlarında genellikle gerginlik vardır. ${ }^{[22,23]}$ Ultrasonografi (US), bilgisayarlı tomografi (BT), manyetik rezonans (MR) ve kemik sintigrafisi başlıca kullanılan görüntüleme yöntemleridir. ${ }^{[24-26]}$ Özellikle MR görüntülemesiyle normal popülasyonda ortalama 3,0 mm kalınlıkta olan ve inflamasyon durumlarında ortalama 7,3 mm'ye kadar kalınlaşan plantar fasyayı net olarak görebiliriz. ${ }^{[6]}$ Tedavisinde antiinflamatuvar ilaçlar, topuk germe egzersizleri, silikon tabanlıklar, steroid enjeksiyonları ve şok dalga terapisi uygulanır (Şekil 3). ${ }^{[2,27-29]}$ Plantar fasiitte silikon tabanlıklar kullanılarak topuk posteromediyali yükseltilir ve mediyal arkın yükünü azaltmak suretiyle

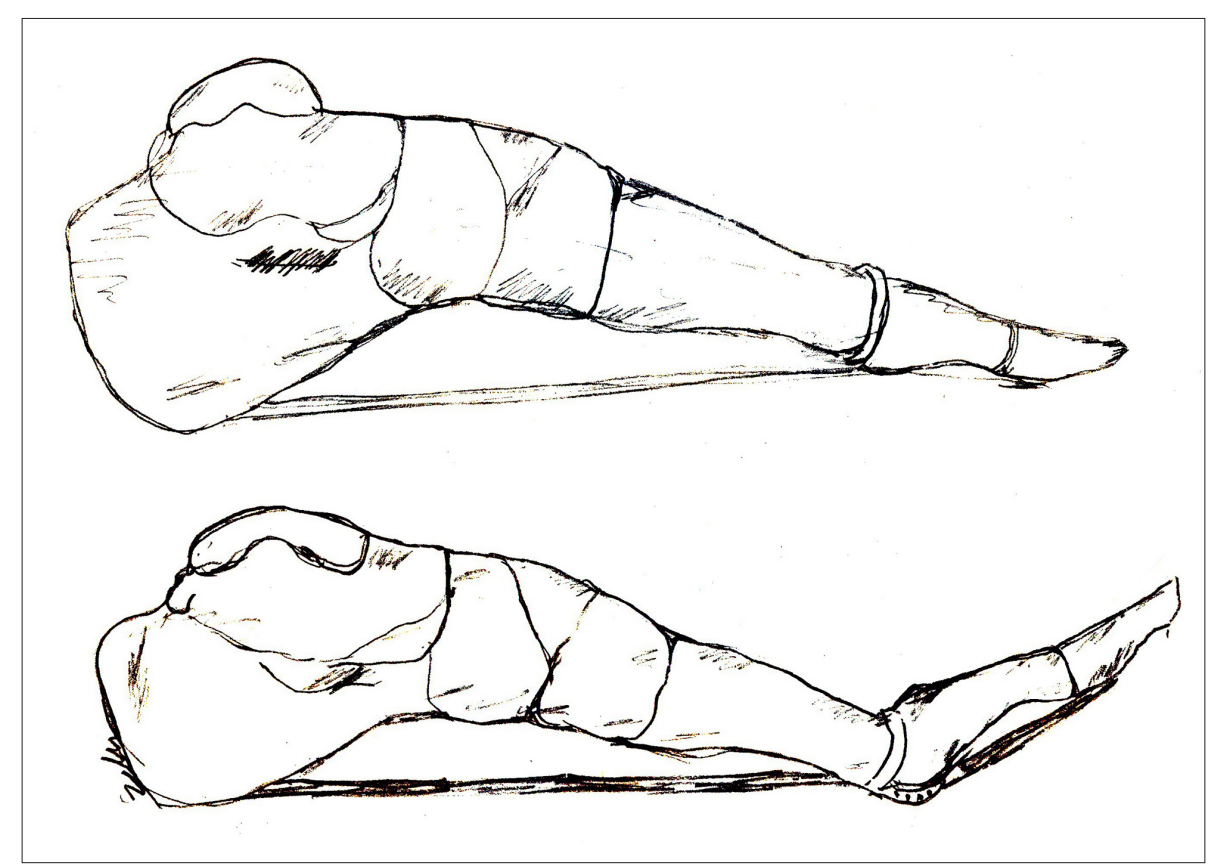

Şekil 2. Parmakların ucunda yürümeyle, parmakların pasif dorsifleksiyonuyla ve plantar fasya üzerine basmakla oluşan hassasiyet plantar fasiit tanısını koymada yardımcı olur.

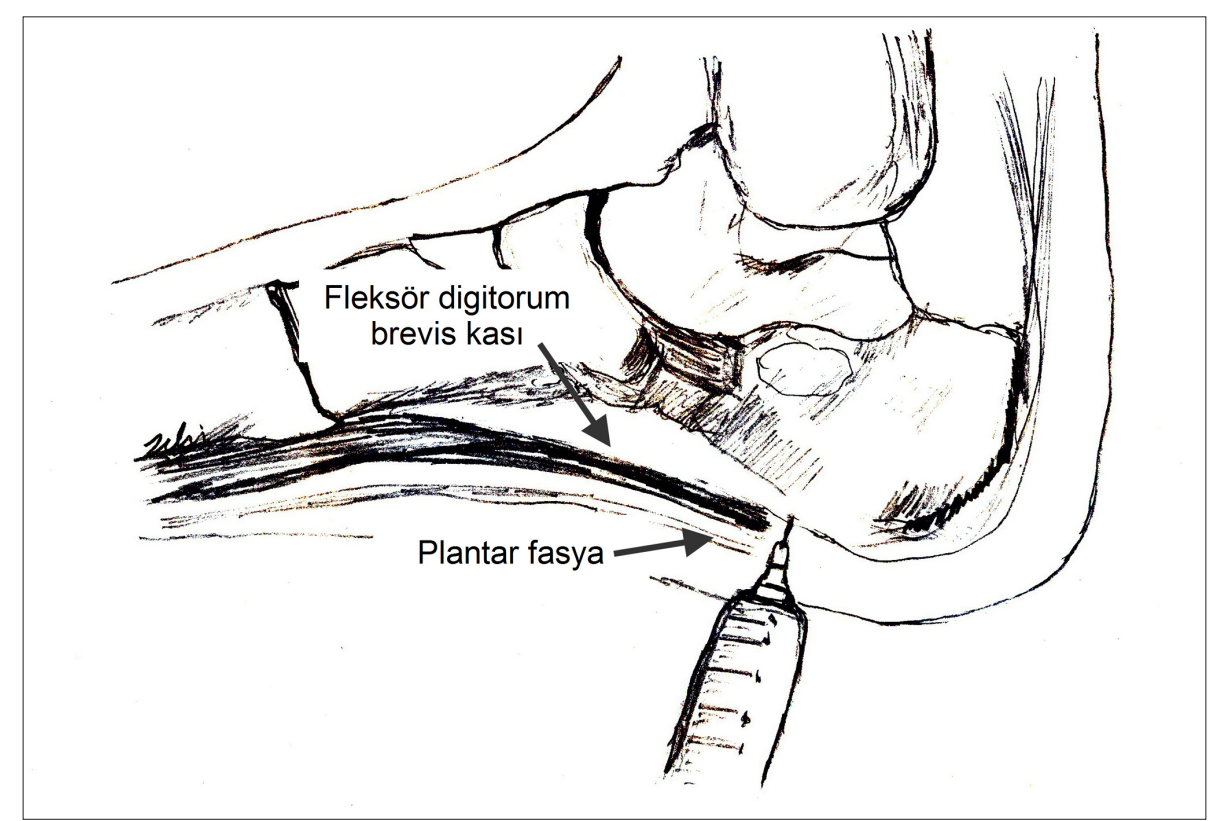

Şekil 3. Kalkaneal spur origosu flexor digitorum brevis'in başlangıç yeridir. Plantar fasiiti olan hastaların tedavisinde steroid enjeksiyonları uygulanır. 
rahatlama sağlanır. ${ }^{[1,16,17,30,31]}$ Bütün bunlar kadar, aktivitelerin kısıtlanması ve değiştirilmesi de önemlidir. Gece ortezleri de konservatif tedaviye dirençli hastalarda kullanılabilir. ${ }^{[32-35]}$ Nadiren cerrahi gerekir. Cerrahi olarak plantar fasyanın gevşetilmesi ayağın uzun arkının statik ve dinamik stabilizasyonunu bozar. ${ }^{[36-40]}$

\section{Plantar fasyanın yırtılması}

Atletik aktivitelerde bulunan kişilerde ve koşucularda aniden başlayan proksimal topuk ağrısı varlığında akla gelmelidir. Plantar fasyanın yırtılması kronik proksimal plantar fasiite kıyasla nadirdir, anamnezle ve fizik muayeneyle rahatlıkla ayırt edilir. Palpasyonla mediyal kalkaneal tuberositasın distalinde proksimal plantar fasyada bir defekt mevcuttur. Ciddi hassasiyetin yanısıra ekimoz da görülür. Genellikle proksimal plantar fasiiti olup daha önce steroid enjeksiyonu ile tedavi edilmiş olan hastalarda görülür. ${ }^{[41-44]}$ Tedavisinde kısa bacak alçı ile immobilizasyon fayda sağlar.

\section{Yağ yastığının dejenerasyonu, atrofisi ve inflamasyonu}

Özellikle 40 yaşından sonra yağ yastığı dejenere olmaya başlar. Zaman içerisinde yapısında yer alan kollajen, elastik doku ve su miktarları azalır. Yağ yastığı genel olarak kalınlığında incelmeye, yapısında yumuşamaya neden olan bu değişiklikler sonrasında şok absorbsiyonu özelliğini yitirir. ${ }^{[2]}$ Yağ yastığının dejenerasyonu ve atrofisi sonucu sert ve düzgün olmayan yüzeylerde yaşlı hastalarda ciddi topuk ağrıları görülür. ${ }^{[6,45]}$ Yağ yastığının atrofisi romatoid artriti olan hastalarda da görülebilir. ${ }^{[46]}$ Genel olarak bu hastalarda yumuşak, düzleşmiş ve kalkaneusun kolaylıkla palpe edildiği bir topuk mevcuttur. Plantar fasya hassas değildir ve ağrı tam topuk altında ve ortadadır. En uygun tedavi şok absorban materyalden yapılmış bir topuk desteği ve topuğun yükseltilerek yükün ön ayağa kaydırılmasıdır. Yağ yastığının inflamasyonunun atrofiden farkı, topuğun incelmemesidir. Aşırı kullanma ve aktivite sonrası oluşan ve dinlenmekle geçen bir ağrıdır. Genellikle travma sonrası yağ yastığının alttaki kemikten ayrılması ile oluşabilir. ${ }^{[2]} \mathrm{MR}$ görüntülemesiyle tanıyı doğrularız. Seperasyonun onarı$\mathrm{m}$ ı altı ay gibi bir sürede oluşur. Bu nedenle bu dönemde yarı sertlikte plastik topuk kapları kullanılarak topuk yağ yastığı stabilize edilir. Steroid enjeksiyonları yağ yastı̆̆ının hem dejenerasyonunda ve atrofisinde hem de inflamasyonunda kontrendikedir. ${ }^{[2]}$ Yağ yastığındaki piezojenik papüller de ayırıcı tanıda düşünülmelidir. ${ }^{[7]}$ Özellikle subkutan yağ dokusunun dermisteki defektlerden herniasyonu patolojinin yağ yastığının kanlanma bozukluğuna bağlı olduğunu düşündürür. ${ }^{[2]}$ Nadiren de olsa glomus tümörü görülebilir. Cerrahi eksizyonu küratiftir. ${ }^{[4]}$

\section{Baxter sinirinin sıkışması}

Posterior tibial sinirden ayrılan lateral plantar sinirden köken alan ve topuğun mediyalinde sıkışan ilk dalıdır (Şekil 4). ${ }^{[48,49]}$ Bu sıkışma sonrasında batıcı

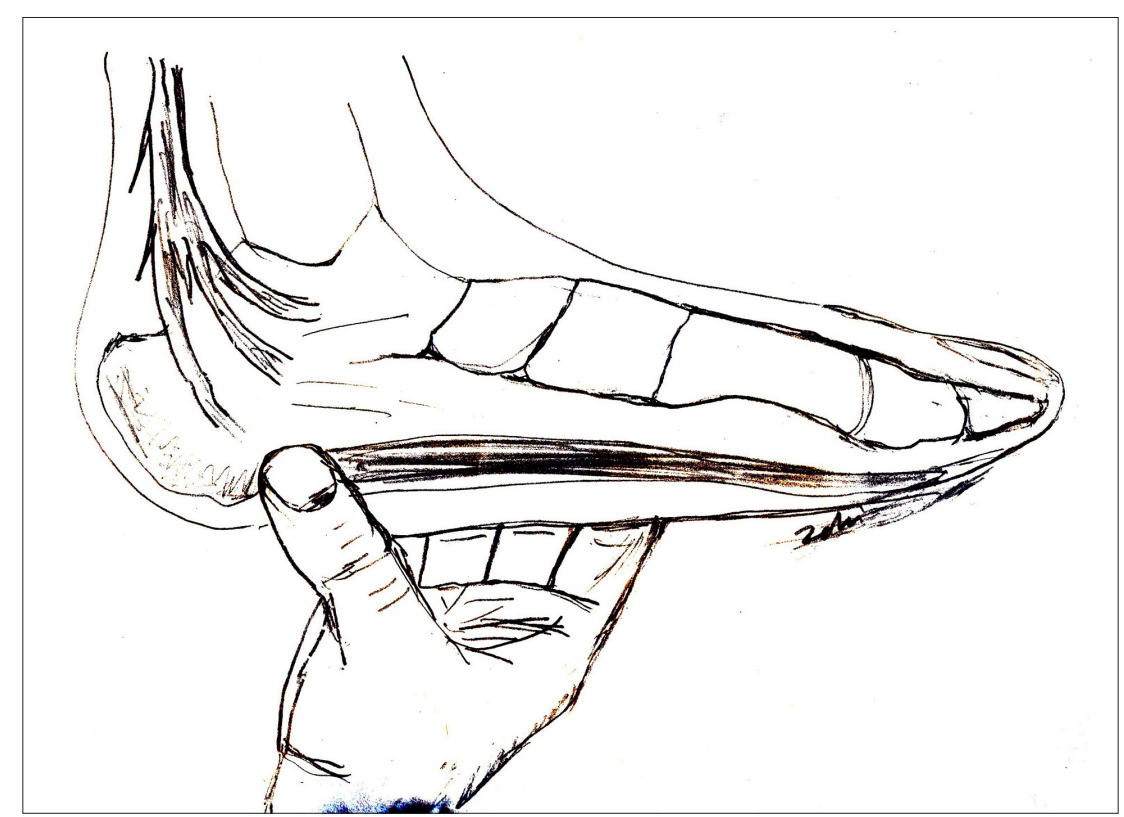

Şekil 4. Posterior tibial sinirden ayrılan lateral plantar sinirden köken alan ve topuğun mediyalinde sıkışan ilk dalı Baxter siniridir. Dansçılar, koşucular ve jimnastikçiler parmak uçlarında kalktıklarında siniri sıkıştıracak kadar iyi gelişmiş abduktor hallusis kasına sahiptirler. 
tarzda topuk ağrısı başta olmak üzere, parestezi ve topuğun mediyalinde hassasiyet görülür. Dansçılar, koşucular ve jimnastikçiler, parmak uçlarında kalktıklarında siniri sıkıştıracak kadar iyi gelişmiş abduktor hallusis kasına sahiptirler. ${ }^{[2]}$ Tedavisinde topuk germe egzersizleri, steroid olmayan antiinflamatuvar (NSAI) ilaçlar, ortezler ve cerrahi gelir. Cerrahi olarak abduktor hallusis kası ile plantar quadratus kası arasındaki fasya gevşetilerek sinirin dekompresyonu sağlanmış olunur.

\section{Kalkaneusun stres kırıkları}

Özellikle koşucularda görülür. Topuğun üzerine tekrarlayarak yansıyan darbeler bu kırığa neden olur. Aşırı kullanım sonucu meydana gelir. ${ }^{[50]}$ Vücut ağırlığıyla birlikte çok şiddetli ağrı oluşur. Muayenesinde kalkaneusun sıkıştırılması ile ağrı daha da şiddetlenir. ${ }^{[2]}$ Çekilen lateral grafilerde şikâyetlerin başlamasından 3-4 hafta sonra sklerotik bir band şeklinde görülür. Genellikle erken dönem olgularda grafilerde hiçbir şey gözükmez. İşte bu dönemde teknesyum-99m ile kemik sintigrafisi faydalı olabilir. Ayrıca MR görüntülemesi de tanıda yardımcı olabilir. Tedavisinde dinlendirmek, aktivitelerin düzenlenmesi, immobilizasyon uygulanır.

\section{Kalkaneus tümörleri}

Özellikle dinlenirken hissedilen kronik topuk ağrısında akla gelmelidir. ${ }^{[2,51,52]}$

\section{Posterior topuk ağrısı}

Retrokalkaneal bursit, yüzeyel Aşil bursiti, kalkaneal egzostos (Haglund deformitesi), Aşil tendiniti ve seronegatif artritlere eşlik eden entesopatiler başlıcalarıdır. Posterior topuk ağrısı plantar ağrıdan sonra ikinci sıklıktadır. Posteriordaki en önemli anatomik yapı posterior kalkaneal tuberositastır. Bu yapının superioruna Aşil tendonu yapışmaktadır. Aşil ile bu kemik çıkıntı arasında retrokalkaneal bursa bulunur. Özellikle dorsifleksiyonda retrokalkaneal bursa, Aşil ile kemik arasında bir tampon rolü oynar. Cilt ile Aşil arasında da yine yüzeyel subkutaneal bir bursa yer alır. Kalkaneusun posterosuperior tuberositasına Haglund çıkıntısı da denir.

\section{Yüzeyel Aşil bursiti}

En sık posterior topuk ağrısı yapan nedendir. Özellikle ayakkabının üst kısmının temas ettiği topuk bölgesinde hassasiyet ve ağıı olur. İnflamasyon oluşması ve ciltte fissürleşme ile giden tabloya Haglund deformitesi adı verilir. Bu tablo ayağa uymayan ayakkabı giyen kadınlarda daha sık görülür. Bu olgularda ayakkabı modifikasyonları önceliklidir. Topuk yükseltme ve topuğu çevreleyen kısmın yumuşatılması gibi konservatif yöntemlere başvurulur. Steroid enjeksiyonları yapılabilir.

\section{Retrokalkaneal bursit}

Kalkaneus ile Aşil tendonunun arasındaki bursanın inflamasyonudur. Özellikle dorsifleksiyonda irrite olan bu bursanın aşırı kullanımına bağlı bir rahatsızlıktır. Haglund topuk adını alan ve kalkaneal superior çıkıntının büyümesiyle karakterize bir tablo oluşabilir. İlk olarak 1928 yılında Haglund tarafından sert ve alçak topuklu ayakkabı ile golf oynayanlarda "kültürlü insan topuğu" olarak tarif edilmiştir. Kadın:Erkek oranı 20:1'e dek çıkar. Etyolojide sistemik hastalıklar (entesopatiler) ve Aşil yapışma anormallikleri de araştırılmalıdır. Tedavide ayakkabı modifikasyonları önceliklidir. NSAI ilaçlar ile tedavi en az üç hafta uygulanmalıdır. Steroid enjeksiyonu yapılabilir. Cerrahi eksizyon da tedaviye dirençli olgularda uygulanabilir. Ayakkabı modifikasyonlarında topuk yükseltme ve Aşil yastığını uzatma ile stabil yürüme sağlanabilir.

\section{Kalsifik tendinit}

Sıklıkla entesopati yapan romatizmal hastalıklara ve Haglund topuğuna eşlik eder. Plantar fleksiyonda ve dorsifleksiyonda topuk posteriorunda krepitasyon hissedilir ve hassasiyet mevcuttur. Çekilen lateral grafilerde kalsifikasyon görülür. Açık arkalı ayakkabılar, topuğu yükseltme, Aşil germe egzersizleri, antiinflamatuvar ilaçlar ve steroid enjeksiyonları tedavideki seçeneklerdir. Nadiren cerrahi gerektirir. Kalsifik depositlerin eksizyonu yarar gösterir.

\section{Aşil tendiniti}

Parmaklarımızın ucunda yükselmeye ve yürümemize yardımcı olan bu tendonun aşırı kullanımı, tendonun kronik hasarı ile sonuçlanır. Bu durumda yürürken topuğun arkasında şiddetli bir ağrı hissedilir. Tedavisinde antiinflamatuvar ilaçlar, fizik tedavi, masaj tedavisi, soğuk uygulama ve immobilizasyon uygulanır.

\section{Entesopatiler}

Sistemik artritik hastalıklar genellikle entesopatik posterior ağrı yapar. Topuk ağrısı bazen romatizmal hastalıklarda ilk ve tek bulgu olabilir. ${ }^{[5,54]} \mathrm{Bu}$ yüzden dikkatlice ele alınmalıdır. Romatoid artritte topuk ağrısı spur oluşumu ile karakterizedir ve genellikle bilateraldir. Tüm seropozitif artritlerde olduğu gibi ciltteki incelme tabloyu ağırlaştııır. Reiter sendromu, psöriasis ve ankilozan spondilit gibi seronegatif artritlerde ise entesopatik gerilme ağrısı mevcuttur. Gut, psödogut ve diyabet gibi sistemik hastalıklarda da plantar topuk ağrısı olabilir. Ağrı daha ziyade plantar fasiiti taklit 
eder. Palyatif tedavi sistemik hastalığın tedavisi ile birlikte yürütülür.

\section{Mediyal topuk ağrısı}

Tarsal tünel sendromu, tibialis posterior tendiniti, flexor hallucis longus tendiniti en önemlileridir.

\section{Tarsal tünel sendromu}

Posterior tibial sinirin ve dallarının flexor retinakulum altında sıkışması sonucu oluşan bir nöropatidir. ${ }^{[2]}$ Post travmatik yapışıkıklar, kemik çıkıntılar, kronik inflamasyon ve selim tümörler sıkışmaya neden olan etiyolojik etkenler arasında sayılabilinir. Arka ayak varusu ve ön ayak pronasyonu tarsal tünel sendromuna sebep olan en önemli mekanik etkendir. Ayak mediyalinde iç malleolden ön ayağa dek yayılan ağrı, yanma ve karıncalanma mevcuttur. Mediyal malleolün inferiorunda ve Licinate bağ altında hassasiyet vardır. Tinnel testi pozitiftir. Tibial sinir innervasyon sahasında iki nokta duyarlılığı azalmıştır. \%25 proksimal ağı yayılımı vardır. Elektromiyografi (EMG) tanı koymada en önemli yöntemdir. İzole topuk ağrısı genellikle tarsal tünel sendromundan uzaklaştırır. En seçkin tedavi yöntemi posterior tibial sinirin ve dallarının dekompresyonudur. Ayak bileğinin mediyal kenarında oluşan batıcı ve yüklenmeyle başlayıp adım atarken de devam eden ağrı da ise kalkaneal dal nörodinisi düşünülebilir. Ağrının diğer bir özelliği ise distale değil topuk mediyalinden topuk yağ yastığına yayılmasıdır. Tedavide mediyal ark destekleri ve cerrahi serbestleştirme en uygun yöntemlerdir.

\section{Tibialis posterior tendiniti}

Hastalar çoğunlukla dördüncü ve beşinci dekatlarında ve planovalgus ayak yapısına sahiptirler. Ayakta aşırı valgus zorlamasına sebep olan tekrarlayıcı hareketler sonucu tibialis posterior tendonun gerilmesi ve kopması sonucu oluşur. Hastanın yürüme kapasitesini düşüren ağrı topuk mediyalinde ve tibialis posterior boyuncadır. Mediyal ark desteği, antiinflamatuvar ilaçlar, kısa bacak ateli ile dinlendirme ve peritendinöz steroid enjeksiyonu tedavi seçenekleridir. Tendon içine yapılan enjeksiyonlar rüptür riskini arttırır.

\section{Kronik fleksör hallusis longus tendiniti}

Topuk mediyalinden başlayıp plantar fasyaya doğru yayılan bir ağrı mevcuttur (Şekil 5). ${ }^{[2]}$ Plantar fasiit ile karışır. Her ikisinde de pasif başparmak dorsifleksiyonu ile ağıı oluşur. Ağrının uzun süreli başparmak fleksiyonunda geçmesi plantar fasiit, artması fleksor hallusis longus (FHL) tendiniti için patognomoniktir. Yararlı tedavi yöntemleri arasında dinlendirme, aktivitelerin düzenlenmesi, germe egzersizleri, soğuk uygulama ve antiinflamatuvar ilaçlar sayılabilir.

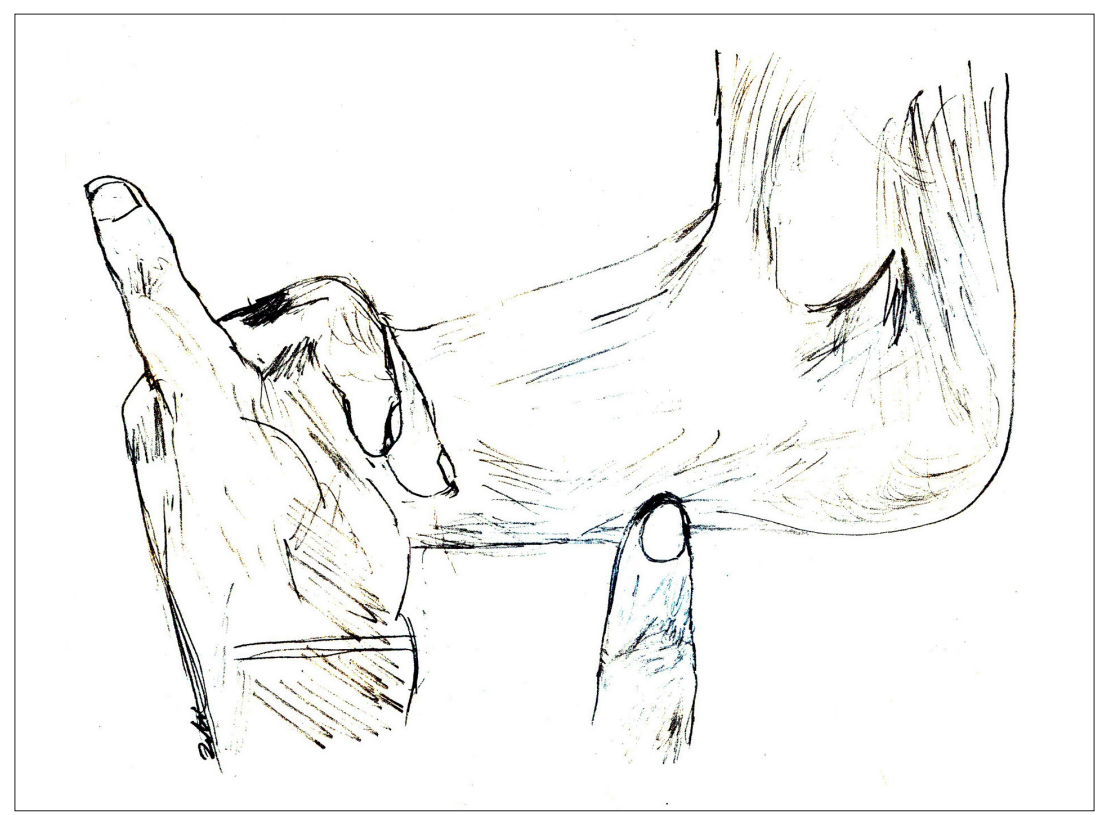

Şekil 5. Her ikisinde de pasif başparmak dorsifleksiyonu ile ağrı oluşur. Ağrının uzun süreli başparmak fleksiyonunda geçmesi plantar fasiit, artması FHL tendiniti için patognomoniktir. 


\section{Lateral topuk ağrısı}

Sıklıkla peroneal tendonların kalkaneus kırı̆gı gibi bir travma ile distorsiyonu sonucu meydana gelir. Ayrıca peroneal tendonlar traselerini terkedip lukse olabilir. Topuk lateralinde ağrı ve hassasiyetin yanı sıra palpe edilebilen peroneal tüberkülün olması tanı koydurur. Tedavide steroid enjeksiyonu yapılır ve cerrahi uygulanır.

\section{ETIYOLOJiK ETKENE GÖRE SINIFLAMA}

Topuk ağrıları ortaya çıkış nedenlerine bağlı olarak, aşırı kullanma sonucu meydana gelen, artritlere eşlik eden, metabolik hastalıklarda görülen ve enfeksiyon hastalıklarında tutulan olmak üzere yine dörde ayrilır.

1- Aşırı kullanma sonucu meydana gelen: Koşucu topuğu, Aşil tendon lezyonları, kalkaneus stres kırıkları.

2- Artritlere eşlik eden: RA, SLE, Ankilozan spondilit, Psoriatik artrit, Reiter sendromu.

3- Metabolik hastalıklarda görülen: Gut, psödogut, diabetes mellitus.

4- Enfeksiyon hastalıklarında tutulan: Tbc, gonore.

\section{KÖKEN ALDIĞI ANATOMIK YAPILARA GÖRE SINIFLAMA}

Topuk ağrıları köken aldıkları yapılara göre, cilt, yağ dokusu, sinir, bursa, tendon, fasya ve kemik olmak üzere yediye ayrılır.

1- Cilt: Hiperkeratoz.

2- Yağ dokusu: Yağ yastığının atrofisi, inflamasyonu, kalkaneustan ayrışması, papülleri.

3- Sinir: Tarsal tünel sendromu, mediyal kalkaneal sinir nöromu, lateral plantar sinirin Baxter dalının sıkışması.

4- Bursa: Yüzeysel Aşil bursiti, retrokalkaneal bursit, Haglund deformitesi.

5- Tendon: Tibialis posterior tendiniti, peroneal tendinit, Aşil tendiniti, flexor hallucis longus tendiniti.

6- Fasya: Plantar fasiit, plantar fasyanın yırtılması.

7- Kemik: Kalkaneal spur, kalkaneus stres kırığı, os trigonum.

Topuk ağrısı etiyolojisinde farklı hastalıkların ve dokuların bulunduğu ciddiye alınması gereken bir yakınmadır. Ağrı lokalizasyonu tanıda belirleyici en önemli faktördür. Ağrı nedeni tam olarak ortaya koyulmadan yapılan tedaviler hem yarar sağlamaz hem de tabloyu daha da ağırlaştırabilir. Çoğunlukla yanlış ayakkabı kullanımına bağlanan ve kalkaneal spur tanısıyla yeterli tetkik yapılmadan eksik tedavi edilen bu yakınma, iyi irdelendiğinde sistemik bir hastalığın ilk belirtisi ya da cerrahi girişim gerektiren bir tablo olarak karşımıza çıkabilmektedir. Topuk ağrısını basit bir yakınma olarak değerlendirmemek gerekir. Nedene yönelik tüm tetkiklerin yapılması, çok fazla tedavi seçeneği arasından uygun olanın saptanması kısa sürede rahatlık sağlamanın en doğru yoludur.

\section{KAYNAKLAR}

1. Gill LH. Plantar fasciitis: diagnosis and conservative management. J Am Acad Orthop Surg 1997;5(2):109-17.

2. Pfeffer GB. Plantar heel pain. Instr Course Lect 2001;50:521-31.

3. Miller WE. The heel pad. Am J Sports Med 1982;10(1):19-21.

4. Sarrafian SK, editor. Anatomy of the Foot and Ankle: Descriptive, Topographic, Functional. Philadelphia, PA: JB Lippincott; 1993.

5. Jahss $\mathrm{MH}$, Michelson JD, Desai P, Kaye R, Kummer F, Buschman W, Watkins F, Reich S. Investigations into the fat pads of the sole of the foot: Anatomy and histology. Foot Ankle 1992;13(5):233-42.

6. Prichasuk S. The heel pad in plantar heel pain. J Bone Joint Surg Br 1994;76(1):140-2.

7. Lin E, Ronen M, Stampler D, Suster S. Painful piezogenic heel papules. A case report. J Bone Joint Surg Am 1985;67(4):640-1.

8. Cardinal E, Chhem RK, Beauregard CG, Aubin B, Pelletier M. Plantar fasciitis: sonographic evaluation. Radiology 1996;201(1):257-9.

9. Hill JJ Jr, Cutting PJ. Heel pain and body weight. Foot Ankle 1989;9(5):254-6.

10. Hedrick MR. The plantar aponeurosis. Foot Ankle Int 1996;17(10):646-9.

11. Hicks JH. The mechanics of the foot. Part II: The plantar aponeurosis and the arch. J Anat 1954;88(1):25-30.

12. Duvries HL. Heel spur (calcaneal spur). AMA Arch Surg 1957;74(4):536-42.

13. Tanz SS. Heel pain. Clin Orthop Relat Res 1963;28:169-78.

14. Karr SD. Subcalcaneal heel pain. Orthop Clin North Am 1994;25(1):161-75.

15. Furey JG. Plantar fasciitis: the painful heel syndrome. J Bone Joint Surg Am 1975;57(5):672-3.

16. Gill LH, Kiebzak GM. Outcome of nonsurgical treatment for plantar fasciitis. Foot Ankle Int 1996;17(9):527-32.

17. Lapidus PW, Guidotti FP. Painful heel: report of 323 patients with 364 painful heels. Clin Orthop Relat Res 1965;39:178-86.

18. Pfeffer G, Bacchetti P, Deland J, Lewis A, Anderson R, Davis W, Alvarez R, Brodsky J, Cooper P, Frey C, Herrick R, Myerson M, Sammarco J, Janecki C, Ross S, Bowman M, Smith R. Comparison of custom and prefabricated orthoses in the initial treatment of proximal plantar fasciitis. Foot Ankle Int 1999;20(4):214-21.

19. Snook GA, Chrisman OD. The management of subcalcaneal pain. Clin Orthop Relat Res 1972;82:163-8.

20. Wolgin M, Cook C, Graham C, Mauldin D. Conservative treatment of plantar heel pain: long-term follow-up. Foot Ankle Int 1994;15(3):97-102. 
21. KiblerWB, Goldberg C, ChandlerTJ. Functional biomechanical deficits in running athletes with plantar fasciitis. Am J Sports Med 1991;19(1):66-71.

22. Carlson RE, Fleming LL, Hutton WC. The biomechanical relationship between the tendoachilles, plantar fascia and metatarsophalangeal joint dorsiflexion angle. Foot Ankle Int 2000;21(1):18-25.

23. Sarrafian SK. Functional characteristics of the foot and plantar aponeurosis under tibiotalar loading. Foot Ankle 1987;8(1):4-18.

24. Wall JR, Harkness MA, Crawford A. Ultrasound diagnosis of plantar fasciitis. Foot Ankle 1993;14(8):465-70.

25. Williams PL, Smibert JG, Cox R, Mitchell R, Klenerman L. Imaging study of the painful heel syndrome. Foot Ankle 1987;7(6):345-9.

26. Berkowitz JF, Kier R, Rudicel S. Plantar fasciitis: MR Imaging. Radiology 1991;179(3):665-7.

27. DiGiovanni BF, Moore AM, Zlotnicki JP, Pinney SJ. Preferred management of recalcitrant plantar fasciitis among orthopaedic foot and ankle surgeons. Foot Ankle Int 2012;33(6):507-12. CrossRef

28. Miller RA, Torres J, McGuire M. Efficacy of first-time steroid injection for painful heel syndrome. Foot Ankle Int 1995;16(10):610-2.

29. Dasgupta B, Bowles J. Scintigraphic localisation of steroid injection site in plantar fasciitis. Lancet 1995;346(8987):1400-1.

30. Lutter LD. Surgical decisions in athletes subcalcaneal pain. Am J Sports Med 1986;14(6):481-5.

31. SpiegI PV, Johnson KA. Heel pain syndrome: which treatments to choose? J Musculoskel Med 1984;1:66-71.

32. Mizel MS, Marymont JV, Trepman E. Treatment of plantar fasciitis with a night splint and shoe modification consisting of a steel shank and anterior rocker bottom. Foot Ankle Int 1996;17(12):732-5.

33. Powell M, Post WR, Keener J, Wearden S. Effective treatment of chronic plantar fasciitis with dorsiflexion night splints: A crossover prospective randomized outcome study. Foot Ankle Int 1998;19(1):10-8.

34. Tisdel CL, Harper MC. Chronic plantar heel pain: treatment with a short leg walking cast. Foot Ankle Int 1996;17(1):41-2.

35. Wapner KL, Sharkey PF. The use of night splints for treatment of recalcitrant plantar fasciitis. Foot Ankle 1991;12(3):135-7.

36. Arangio GA, Chen C, Kim W. Effect of cutting the plantar fascia on mechanical properties of the foot. Clin Orthop Relat Res 1997;(339):227-31.
37. Huang CK, Kitaoka HB, An KN, Chao EY. Biomechanical evaluation of longitudinal arch stability. Foot Ankle 1993;14(6):353-7.

38. Katoh Y, Chao EY, Laughman RK, Schneider E, Morrey BF. Biomechanical analysis of foot function during gait and clinical applications. Clin Orthop Relat Res 1983;(177):23-33.

39. Kitaoka HB, Luo ZP, An KN. Mechanical behavior of the foot and ankle after plantar fascia release in the unstable foot. Foot Ankle Int 1997;18(1):8-15.

40. Thordarson DB, Kumar PJ, Hedman TP, Ebramzadeh E. The effect of partial versus complete plantar fasciotomy on the windlass mechanism. Foot Ankle Int 1997;18(1):16-20.

41. Anderson RB, Foster MD. Operative treatment of subcalcaneal pain. Foot Ankle 1989;9(6):317-23.

42. Leach R, Jones R, Silva $\mathrm{T}$. Rupture of the plantar fascia in athletes. J Bone Joint Surg Am 1978;60(4):537-9.

43. Sellman JR. Plantar fascia rupture associated with corticosteroid injection. Foot Ankle Int 1994;15(7):376-81.

44. Bordelon RL. Subcalcaneal pain. A method of evaluation and plan for treatment. Clin Orthop Relat Res 1983;(177):49-53.

45. Jørgensen $U$. Achillodynia and loss of heel pad shock absorbency. Am J Sports Med 1985;13(2):128-32.

46. Resnick RB, Hudgins LC, Buschmann WR, Kummer FJ, Jahss $\mathrm{MH}$. Analysis of the heel pad fat in rheumatoid arthritis. Foot Ankle Int 1999;20(8):481-4.

47. Quigley JT. A glomus tumor of the heel pad. A case report. J Bone Joint Surg Am 1979;61(3):443-4.

48. Baxter DE, Thigpen CM. Heel pain - operative results. Foot Ankle 1984;5(1):16-25.

49. Przylucki $\mathrm{H}$, Jones $\mathrm{CL}$. Entrapment neuropathy of muscle branch of lateral plantar nerve: a cause of heel pain. J Am Podiatry Assoc 1981;71(3):119-24.

50. Protzman RR, Griffis CG. Stress fractures in men and women undergoing military training. J Bone Joint Surg Am 1977;59(6):825.

51. Hertzanu Y, Mendelsohn DB, Gottschalk F. Aneurysmal bone cyst of the calcaneus. Radiology 1984;151(1):51-2.

52. Khermosh O, Schujman E. Benign osteoblastoma of the calcaneus. Clin Orthop Relat Res 1977;(127):197-9.

53. Gerster JC. Plantar fasciitis and Achilles tendinitis among 150 cases of seronegative spondyloarthritis. Rheumatol Rehabil 1980;19(4):218-22.

54. Gerster JC, Piccinin P. Enthesopathy of the heels in juvenile onset seronegative B-27 positive spondyloarthropathy. J Rheumatol 1985;12(2):310-4. 